\title{
TEMPESTADES GEOMAGNETICAS E O EVENTO CARRINGTON
}

\section{GEOMAGNETIC STORMS AND CARRINGTON EVENT}

\section{Gerson Antonio Santarine ${ }^{1}$; Roberto Naves Domingos ${ }^{1,2}$}

\author{
${ }^{1}$ Departamento de Física, Instituto de Geociências e Ciências Exatas, UNESP campus \\ de Rio Claro, Rio Claro, SP. E-mail santarin @ rc.unesp.br \\ ${ }^{2}$ Centro de Estudos Ambientais, UNESP campus de Rio Claro, Rio Claro, SP. E-mail \\ rnaves@rc.unesp.br
}

\begin{abstract}
RESUMO
Catástrofes podem ser entendidas como o resultado de eventos adversos que causam impactos na Sociedade. O desenvolvimento científico, além de aprofundar o entendimento de antigos fenômenos naturais, abriu novas perspectivas para descobertas de diversos outros, até então desconhecidos, revelando situações potencialmente perigosas para o meio ambiente que, até então, permaneciam insuspeitas. Nessa classe de eventos extremos situam-se as tempestades geomagnéticas. Trata-se de tormentas provocadas pelas enormes ejeções de massa coronal do Sol, ao atingirem a magnetosfera terrestre. Se a Terra estiver diretamente na linha de visada de uma rajada coronal, uma onda de choque das partículas energéticas carregadas provenientes do astro provocará uma tempestade geomagnética devido à sua interação abrupta com campo magnético terrestre. No espaço os satélites serão os primeiros artefatos seriamente afetados pelo transiente energético, devido à alta probabilidade de queima dos componentes eletrônicos a bordo, provocando colapsos nos sistemas de comunicações. Também podem ter suas órbitas modificadas pelo arrasto aerodinâmico provocado pelo aumento da espessura da atmosfera após o aquecimento das camadas superiores, consequência da absorção do pulso eletromagnético da erupção solar. Na superfície, dependendo da magnitude da tempestade, a flutuação magnética com a consequente indução da sobrecarga nos cabos de transmissão de energia poderá provocar a queima de transformadores em curtos-circuitos generalizados. No século XIX, a Terra foi atingida por uma enorme ejeção coronal (a mais intensa a atingir a Terra de que se tem registro histórico) a qual ficou conhecida como evento Carrington, ocorrido em 1859, com relatos de inúmeros prejuízos no hemisfério norte. Este texto analisará, de maneira sucinta, as tempestades geomagnéticas e algumas possíveis consequências para a moderna sociedade tecnológica caso um evento semelhante ao Carrington venha a ocorrer na atualidade.

Palavras-chave: Tempestade Geomagnética. Tempestade Solar. Evento Carrington. Erupção Solar.
\end{abstract}

\begin{abstract}
Disasters may be understood as a result of adverse events that produce impacts on society. The scientific development, as well as deepen the understanding of ancient natural phenomena, opened new prospects for discovered several other, as yet unknown, revealing potentially dangerous situations for the environment that, until then, remained unsuspected. In this class of extremes events lie the geomagnetic storms. This is caused by the massive storms coronal mass ejections from the Sun to reach Earth's magnetosphere. If Earth is directly in line sight of a coronal blast, a
\end{abstract}


shock wave of energetic charged particles from the star will cause a geomagnetic storm due to its abrupt interaction with terrestrial magnetic field. Satellites in space will be the first artifacts seriously affected by energy transient due a high probability of firing onboard electronics components, causing breakdowns in communication systems. Also may have its orbits altered by aerodynamic drag caused by increase of atmosphere thickness after heating the upper layers, as result of electromagnetic pulse absorption from solar flare. On surface depending on the storm magnitude, magnetic fluctuations with consequent induction of overhead power transmission cables will cause burning on transformers in generalized short circuits. On nineteenth century Earth has been hit by a tremendous (more intense reaching Earth that has historical record) coronal ejection which was known as Carrington event, occurred in 1859, with reports innumerable injury on northern hemisphere. This article analyzes, succinctly, geomagnetic storms and some possible consequences for modern technological society case similar to Carrington event will occur today.

Keywords: Geomagnetic Storm. Solar Storm. Carrington Event. Solar Eruption.

Catástrofes podem ser entendidas como o resultado de eventos adversos que causam impactos na sociedade. Distinguidas principalmente em função de sua origem podem ou não serem agravadas pelas atividades antrópicas. Descontinuidades em serviços essenciais como transporte, fornecimento de água, comunicação, luz, saúde, bem como, atividades industriais e comerciais estão diretamente associados à sua magnitude.

A Humanidade tem se desenvolvido ao longo dos milênios convivendo com inúmeras catástrofes ambientais as quais podem ocorrer em qualquer lugar, vez que, os fenômenos naturais que as desencadeiam (tempestades, erupções vulcânicas, terremotos e outros) não são necessariamente especificidades de determinada região.

Com o desenvolvimento tecnológico da atualidade inúmeras técnicas de previsões de tragédias naturais puderam ser e aperfeiçoadas no intuito de mitigar ou minimizar seus efeitos. $\mathrm{O}$ avanço da Ciência tem aprofundado o entendimento de antigos fenômenos naturais abrindo perspectivas para descobertas de diversos outros até então desconhecidos, revelando situações insuspeitas de potencial perigo. Nesta classe de eventos extremos que começam a ser compreendidos, encontram se as tempestades geomagnéticas provocadas pelas erupções solares.

O Sol sempre foi objeto de adoração em diversas culturas ao longo da história por ser concebido como sendo a fonte suprema para vida. Esta concepção é bastante natural para os seres humanos, vez que na atualidade fica difícil imaginar a existência da vida planetária sem sua influencia.

Os estudos científicos sistemáticos do Sol tiveram inicio no século dezessete a partir de invenção do telescópio em 1609. Somente em meados da década de $80 \mathrm{com}$ o advento dos satélites especificamente projetados para observações do astro rei é que se pode vislumbrar uma melhor compreensão de seu funcionamento e a magnitude de sua interação com o planeta. As manchas solares conhecidas desde a antiguidade foram os alvos naturais e imediatos das observações. A compreensão dos mecanismos que as produzem permitiu aos estudiosos relacioná-las as potenciais ameaças que podem representar para nossa complexa sociedade tecnológica.

Até a pouco ninguém suspeitava que as explosões solares associadas a elas pudessem desencadear graves distúrbios geomagnéticos com reflexos econômicos e sociais insuspeitos, mas os registros históricos de um evento ocorrido no hemisfério norte em 1859 não deixaram duvidas quanto à ameaça potencial que representam. Naquele ano o astrônomo inglês R. C. Carrington descreveu a explosão de duas manchas solares próximas e de grande brilho, na direção da Terra, no exato instante que estas aconteciam. Pouco tempo depois seu impacto foi sentido em todo o planeta, principalmente nos Estados Unidos com a interrupção das comunicações telegráficas naquele país. Em todo o hemisfério norte auroras boreais multicoloridas iluminaram o céu noturno com brilho 
muito intenso. O real significado daquele evento só foi compreendido mais de um século depois. O texto aqui reportado aborda de forma sucinta aspectos relacionados ao clima espacial descrevendo alguns dos principais mecanismos envolvidos nas tempestades geomagnéticas. Rememora o episodio descrito por Carrington e analisa brevemente algumas possíveis consequências de uma intensa tormenta solar sobre o planeta nos dias atuais. O interesse por este tema se justifica devido à vulnerabilidade da moderna sociedade em face à total dependência da energia elétrica.

\section{ESTRUTURA DO SOL}

Situado a uma distância de cento e cinquenta milhões de quilômetros da Terra o Sol constitui se de uma esfera de gás composta de hidrogênio 74,9\%, hélio $23,8 \%$, e traços de elementos tais como, oxigênio, ferro, silício, enxofre, níquel dentre outros. $O$ astro gera sua energia através do processo nuclear de fusão do hidrogênio convertido em hélio com predominância para o ciclo próton-próton. Está situado na classe espectral G2 com uma temperatura superficial de aproximadamente $5800 \mathrm{~K}$ fazendo parte, como a maioria das estrelas, da sequencia principal do diagrama que relaciona a luminosidade da estrela com sua temperatura. (diagrama de Hertzsprung-Russel). Orbita o centro da Via Láctea a uma distância aproximadamente vinte e seis mil anos-luz do centro galáctico completando uma órbita em aproximadamente duzentos e quarenta milhões de anos a uma velocidade orbital de $250 \mathrm{~km} \mathrm{~s}^{-1}$. O Sol pode ser dividido regiões distintas a partir de sua superfície para o centro conforme se segue ilustrado no esquema abaixo:

A fotosfera com temperatura de $5800 \mathrm{~K}$ e aproximadamente trezentos e trinta quilômetros de espessura compreende a camada visível do astro. Logo abaixo está situada a zona de convecção que se estende até mais ou menos quinze por cento do raio solar. Em seguida encontra-se a camada relativa à zona radiativa por onde a energia do núcleo é retirada. Finalmente o núcleo com temperaturas de milhões de graus Kelvin, local da produção de energia através das reações termonucleares.

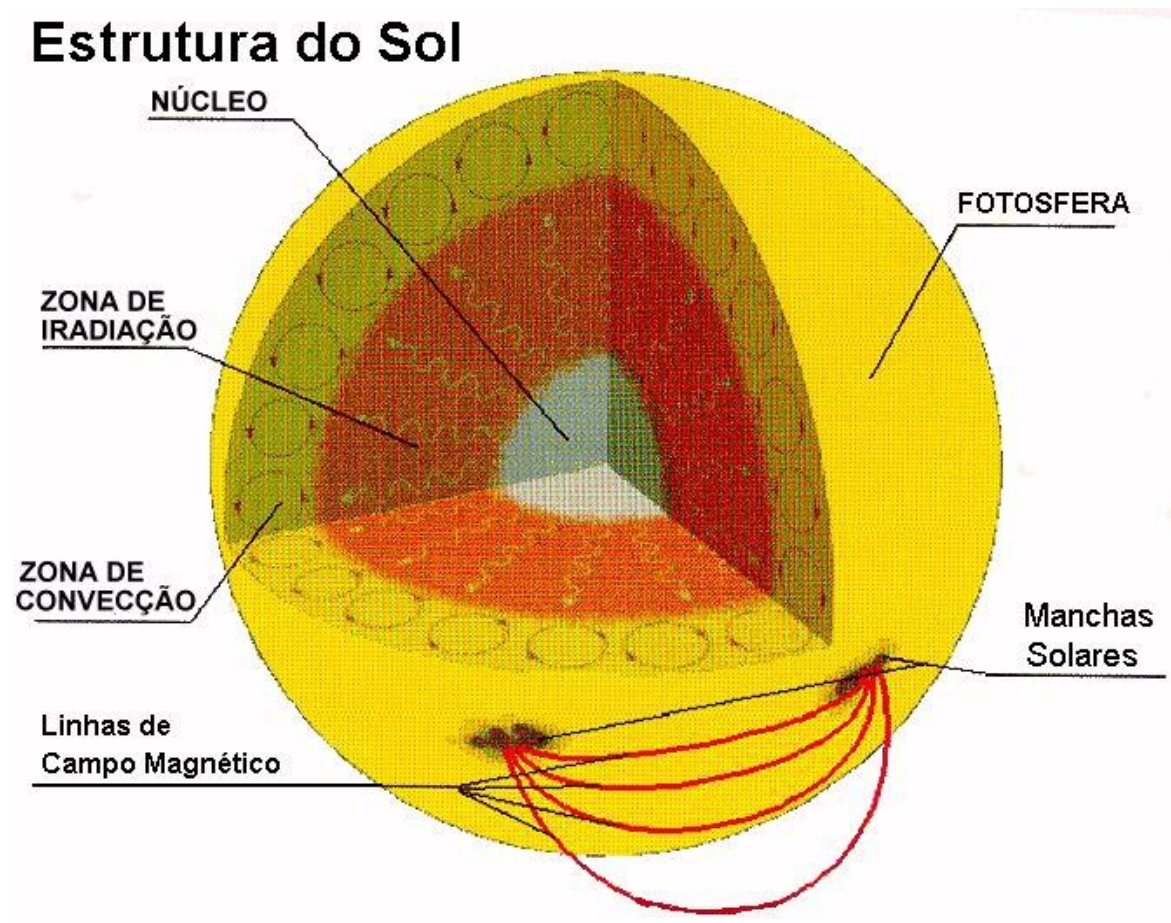

Figura 1. Esquema ilustrativo da estrutura do Sol. Fonte: http://www.cdcc.sc.usp.br/cda/producao/sbpc94/fems-04.jpg 
Acima da fotosfera situa-se a cromosfera estendendo-se por dez mil quilômetros e a partir daí, a coroa solar com comprimento de dois raios solares. Nesta região as temperaturas chegam a dois milhões de graus. Dois mecanismos estão envolvidos no aquecimento desta ultima região. Um consiste na transferência de energia através de ondas sonoras ou magneto-hidrodinâmicas produzidas por turbulência na zona de convecção, as quais se movimentam para a superfície e se dissipam depositando sua energia em forma de calor. $O$ outro se relaciona ao aquecimento magnético onde a energia magnética é estocada continuamente através das grandes erupções solares.

Na zona convectiva do astro o plasma não é suficientemente denso e quente para transferir o calor do interior do Sol para fora somente pelo mecanismo de radiação. Como consequência, as correntes de massa depositam material deste interior mais quente na superfície mais fria. Assim, a temperatura desta massa diminui na superfície, retorna ao interior da zona convectiva para se reaquecer, recomeçando o ciclo térmico. Estas correntes de deslocamentos produzem campos magnéticos variáveis em toda a superfície do Sol. As regiões com pequenas reduções de temperatura e pressão são visíveis no disco solar como manchas escurecidas. Apesar de serem conhecidas há muito tempo, só recentemente as manchas solares receberam maior atenção dos astrônomos por estarem associadas às ejeções de massa coronal. Os períodos associados com a maior ou menor quantidade destas manchas são conhecidos como ciclo de Schwabe, indicando mudanças da atividade solar em intervalos de aproximadamente onze anos.

\section{EJEÇÕES DE MASSA CORONAL}

Ejeções de massa coronal (a fotografia abaixo ilustra, como exemplo, um evento de ejeção coronal em 24/01/2007) são enormes erupções de gás ionizado a altíssimas temperaturas procedentes da superfície do Sol, constituindo-se parte do vento solar.

A maioria das ejeções origina-se nas regiões superficiais a partir de grupos de manchas solares associadas aos campos magnéticos instáveis. As ejeções coronais acontecem como consequência dos diferentes períodos de rotação do astro no equador e polos. Uma rotação do equador solar dura vinte e cinco dias terrestres enquanto a dos polos trinta e cinco. Isto faz com que as linhas de forças dos campos magnéticos locais gerados pelo plasma se estiquem e se distorçam. Ao longo de cada linha fluem enormes quantidades de plasma superaquecido (bilhões de toneladas de material) que, ao se romperem, liberam enormes quantidades de energia e material para o espaço. Isto é essencial para que haja a reconexão magnética das linhas de campo. Em outras palavras, para que ocorra uma ejeção de massa coronal, as linhas de campo fechadas com intensidade suficiente para conter o plasma se enfraquecem e se rompem. Este rearranjo possibilita a liberação repentina da energia acumulada das linhas originais para que ocorra uma nova reconexão magnética. 


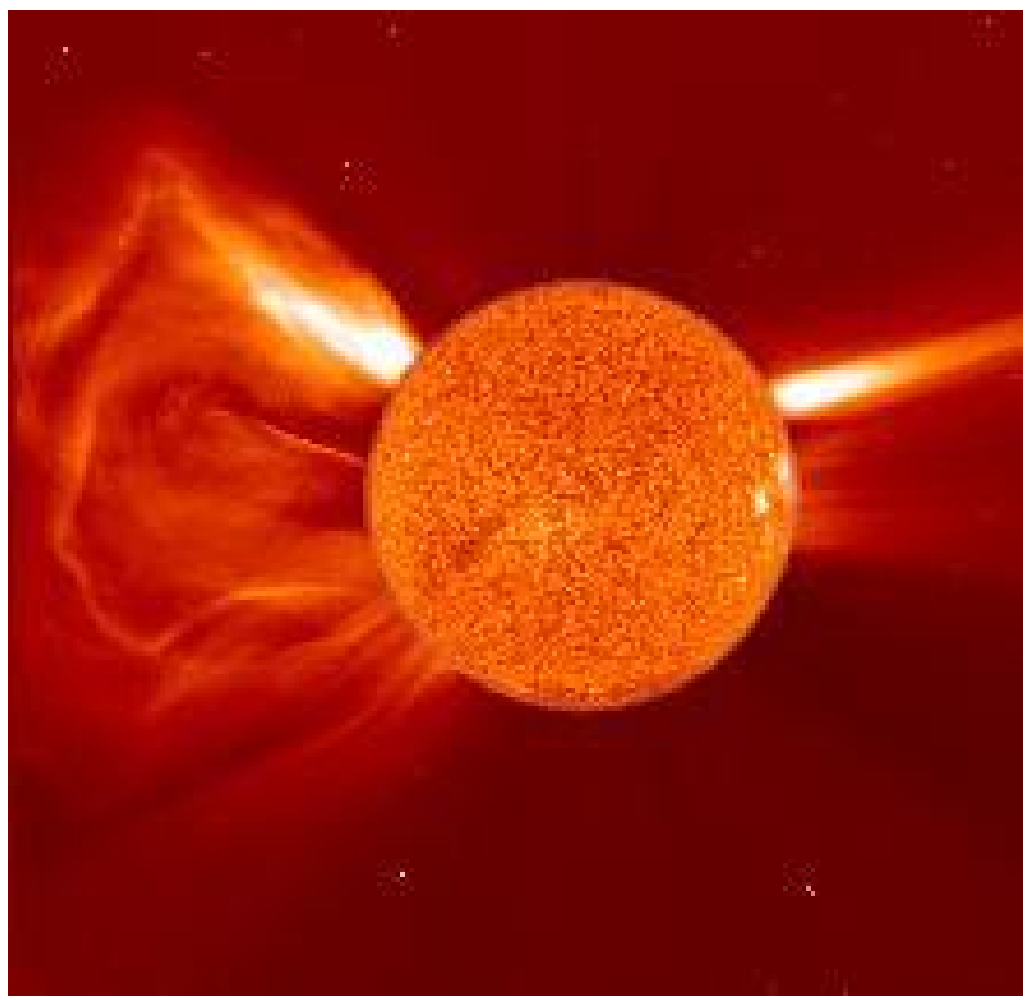

Figura 2. Fotografia de uma ejeção de massa coronal tirada em 24 de janeiro de 2007. Fonte: http://sohowww.nascom.nasa.gov/gallery/SolarCorona/combo001.html

O material ejetado (vento solar) expande-se continuamente no espaço em uma torrente de plasma altamente ionizado a velocidades relativísticas. Esta corrente de partículas carregadas pode se estender até a heliopausa, cerca de cem unidades astronômicas de seu centro. As ejeções coronais liberam enormes quantidades de matéria na forma de plasma (prótons e elétrons, mas também núcleos como hélio, oxigênio e ferro) alem de pulsos de radiação eletromagnética ao espaço. Em ciclos de máxima atividade solar são produzidas de duas a três ejeções de coronais diariamente, enquanto que em épocas de atividade mínima, uma ejeção a cada cinco dias em media é observada. Em uma ejeção coronal parte do gás ionizado expelido retorna à superfície solar por efeito gravitacional enquanto a outra pode se dirigir diretamente para as órbitas planetárias.

\section{TEMPESTADES GEOMAGNETICAS}

Caso a Terra esteja situada na linha de visada de uma ejeção coronal, uma onda de choque de partículas carregadas de alta energia pode causar uma tempestade geomagnética ao perturbar a magnetosfera terrestre. Nestas perturbações as linhas do campo magnético terrestre voltado para o Sol serão comprimidas enquanto que, no lado oposto serão expandidas, gerando uma grande cauda magnética. A reconexão destas linhas campo em sua região expandida liberará enorme quantidade de energia acumulada (da ordem de terajoules). Dependendo da intensidade das reconexões, diferentes níveis de perturbações elétricas podem ocorrer principalmente em latitudes mais altas onde o efeito é mais pronunciado. Como consequência, estes transientes magnéticos podem interromper as transmissões de radio, provocar danos irreversíveis em satélites ou induzir elevadas correntes elétricas nas linhas de distribuição de energia com a possibilidade de danos permanentes para os equipamentos. A flutuação magnética ao induzir sobrecarga nos cabos de transmissão de energia, em casos extremos, pode provocar a queima de transformadores acarretando prejuízos para 
o fornecimento de energia para residências, indústrias, hospitais etc. Sistemas de comunicações como sinais de TV, celulares e radio navegação (GPS) também podem sofrer colapsos por tempo indeterminado.

Dentre as características mais notáveis das tempestades geomagnéticas estão as auroras polares. A grande maioria das partículas eletricamente carregadas é defletida pelo campo magnético da Terra sendo que as mais energéticas conseguem penetrar a magnetosfera. Assim, ao colidirem com os gases atmosféricos como o oxigênio e o nitrogênio produzem por excitação direta, radiação eletromagnética na região visível do espectro. Luzes bruxuleantes coloridas aparecem no céu em altitudes aproximadas de sessenta quilômetros. Formas luminosas variadas como arcos, raios, laminas e outras, proporcionam um raro espetáculo visual. Estas luzes podem ser visíveis por horas a fio e tem sua intensidade luminosa modulada pela magnitude da ejeção solar. O tempo médio para que uma ejeção coronal atinja o planeta é de alguns dias enquanto o pulso eletromagnético demora 8 minutos e 15 segundos para percorrer a mesma distancia. No caso de uma rajada coronal intensa sobre o planeta, os satélites serão os primeiros artefatos a serem seriamente afetados pelo transiente magnético devido à alta possibilidade de queima dos circuitos eletrônicos dos componentes a bordo. Também podem ter suas orbitas modificadas pelo o arrasto aerodinâmico induzido pelo aumento da espessura atmosférica.

Este efeito é consequência direta do aquecimento das camadas superiores pelo pulso eletromagnético da erupção. Isto é algo significativo, pois se considera que tal efeito tenha sido um dos responsáveis pela queda do laboratório espacial orbital SKYLAB em 1979. Outra grande preocupação direciona-se aos astronautas em missões espaciais que, sujeitos as altas doses de radiação estarão propensos às doenças podendo até mesmo levá-los ao óbito. A propagação das ondas de radio na ionosfera (camada ionizada situada entre cinquenta e quinhentos de altitude) torna-se seriamente afetada pelos distúrbios solares. As comunicações podem ser interrompidas, principalmente na faixa de ondas curtas nos os períodos de grande atividade solar.

Desde sua formação o planeta já foi atingido incontáveis vezes por grandes tormentas solares das mais variadas intensidades. Registros no gelo acumulado em camadas nos polos durante milênios podem dar pistas importantes da atividade solar sobre a Terra no passado remoto. Finas camadas de nitrato produzidas pelo bombardeio das radiações no nitrogênio atmosférico precipitam e ficam aprisionadas nas geleiras. Ao serem analisados, os testemunhos de gelo possibilitam a reconstrução da história de eventos solares anteriores às observações astronômicas confiáveis. Dados recolhidos nas geleiras da Groenlândia evidenciaram que acontecimentos solares de magnitude extrema podem ocorrer com probabilidade de uma vez a cada quinhentos anos.

\section{O EVENTO CARRINGTON: A SUPERTEMPESTADE SOLAR DE 1859.}

Apesar da Terra já ter sido bombardeada no passado por incontáveis ejeções de massa coronal de grandes intensidades, a supertempestade solar de 1859 possibilitou pela primeira vez uma avaliação direta de seu impacto na sociedade humana nos primórdios da Revolução Industrial. Ficou conhecido como evento Carrington em homenagem ao astrônomo inglês Richard C. Carrington que a observou no exato instante que acontecia. Em artigo publicado naquele mesmo ano (Carrington 1859) o autor escreveu que, pouco antes do meio dia de 01 de setembro estava observando o Sol como de costume quando começou a registrar em um anteparo um conjunto de manchas na superfície do astro. De súbito enxergou o que mais tarde descreveu como "duas manchas de luz intensamente brancas e brilhantes" em uma região de manchas solares mais escurecidas.

Nas palavras textuais do autor o impressionante relato: "I saw I was an unprepared witness of a very different affair. I thereupon noted down the time by chronometer, and seeing the outburst to be very rapidly on the 
increase, and being somewhat flurried by the surprise, I hastily ran to call someone to witness the exhibition with me, and on returning within 60 seconds, was mortified to find that it was already much changed and enfeebled. Very shortly afterwards the last trace was gone and although I maintained a strict watch for nearly an hour no recurrence took place”.

Em tradução livre: "Eu vi que eu era uma testemunha desprevenida de um assunto muito diferente. Logo após eu anotei o tempo do cronômetro, e vendo a explosão ser muito rápida e a aumentar, e tomado pela surpresa, rapidamente corri para chamar alguém para testemunhar a exibição comigo, e ao voltar dentro de 60 segundos, fiquei mortificado ao descobrir que ela já estava muito alterada e enfraquecida. Muito pouco tempo depois o último vestígio foi embora e embora eu tenha mantido uma estrita vigilância por quase uma hora não houve recorrência".

O que Carrington testemunhou constituiu-se na inequívoca prova de uma enorme erupção solar em direção a Terra. Em cinco minutos as manchas brilhantes desapareceram por completo, mas em pouco tempo, seu impacto foi sentido em todo o planeta. Naquela noite as comunicações telegráficas em todo o mundo começaram a apresentar falhas com relatos de faíscas elétricas e chamas nas linhas de transmissão. Principalmente nos Estados Unidos, mas também em todo o hemisfério norte transformador das linhas elétricas pegaram fogo e derreteram. Auroras coloridas iluminaram o céu noturno com brilho tão intenso que os pássaros se puseram a cantar anunciando o nascer do sol.

Carrington afortunadamente havia registrado a verdadeira causa dos acontecimentos bizarros que assombravam a população. A enorme ejeção de massa coronal na direção da Terra (energia equivalente a bilhões de armas atômicas detonadas ao mesmo instante) resultou na maior supertempestade geomagnética já registrada a atingir o planeta. Várias linhas telegráficas em toda a América do Norte ficaram inoperantes ou danificadas por aquele evento. Relatos de um operador de telégrafo de Pittsburgh informavam que as correntes elétricas nos fios eram tão altas que os contatos dos circuitos entraram em fusão. Assim que a rede telegráfica voltou a operar várias mensagens sobre o evento das luzes celestiais puderam ser trocadas com as descrições presenciadas por testemunhas das diversas regiões dos Estados Unidos.

Uma testemunha ocular na ilha de Sullivan na Carolina do Sul (EUA) relatou: "O céu oriental apareceu de uma cor vermelha sangue". Parecia mais brilhante exatamente no leste, como se a lua cheia, ou melhor, o sol estava prestes a subir. Ele estendeu quase até o zênite e toda a ilha estava iluminada. O mar refletiu o fenômeno, $e$ ninguém podia olhar para ele sem pensar na passagem da Bíblia que diz: "o mar se transformou em sangue."

Em várias cidades diversas pessoas saíram às ruas para testemunhar a pirotecnia celeste. Jornais franceses destacaram descrições das luzes celestes brilhantes que transformou a noite em dia. As auroras também foram avistadas em baixas latitudes como em Cuba e na Jamaica. Fotografias de época testemunham o derretimento de transformadores utilizados na rede elétrica dos Estados Unidos.

$\mathrm{Na}$ atualidade, durante a madrugada de 13 de março de 1989 foi a vez da província de Quebec no Canadá sofrer um colapso no fornecimento de energia elétrica com paralisação de todos os serviços essenciais. A cidade estava enfrentando um inverno com temperaturas de menos quatro graus centígrados quando, subitamente às duas horas e quarenta e quatro minutos um grande transformador da rede elétrica em Montreal sofreu uma violenta sobrecarga, mergulhando a região de seis milhões de pessoas em completa escuridão. Toda a rede elétrica deixou de funcionar em menos de 90 segundos só sendo possível religá-la doze horas mais tarde. A sobrecarga no transformador foi causada pelos efeitos de uma enorme explosão solar, monitorada pelos astrônomos três dias antes. A enorme onda de radiação que se chocou contra a atmosfera da Terra naquela latitude produziu alem dos danos na rede de distribuição de energia, as tremeluzentes luzes avistadas do Alasca ao México. Os pesquisadores estimaram que este evento liberou o equivalente a um terço da energia envolvida no evento de Carrington de 1859. 


\section{DISCUSSAO}

O evento Carrington de 1859 constituiu-se na maior ejeção de massa coronal a atingir a Terra de que se tem registro histórico. A explosão arremessou bilhões de toneladas de prótons e elétrons e assim que estas partículas interagiram com o campo magnético do planeta, poderosas correntes elétricas induzidas sobrecarregaram e queimaram vários transformadores e circuitos elétricos. Auroras espetaculares puderam ser avistadas por todo o globo mesmo nas baixas latitudes. A prova definitiva do potencial perigo das erupções solares foi o acontecimento de Quebec que, desconectando toda a província em questão de minutos teve como consequência a interrupção dos serviços essenciais por horas a fio.

Para os especialistas o que se coloca não é a questão de se uma tormenta solar de proporções épicas pode ou não acontecer, mas quando irá ocorrer. De acordo com os estudiosos é impossível de se prever quando a próxima tempestade solar perfeita vai direcionar sua rajada coronal para a Terra, mas na hipótese de um evento de tal magnitude, não fica difícil de imaginar um cenário de desastre ocasionado pelo impacto sobre a malha elétrica da região afetada. Um cataclismo com estas características poderia provocar rupturas sociais e prejuízos econômicos consideráveis. Nos países desenvolvidos o custo potencial estimado estaria na casa dos poderia ser de trilhões de dólares nos primeiros anos, com reflexos inimagináveis. A interdependência do sistema de transmissão/distribuição de energia em serviços essenciais como: abastecimento de água, tratamento de esgotos, transporte de mercadorias e alimentos, sistema financeiro, rede de telecomunicações, sistemas de navegação GPS e agricultura, dentre outros estão entre os maiores desafios, em razão das linhas serem projetadas para operarem com altas tensões em extensas áreas, o que as torna particularmente vulneráveis.

Apesar de poucos duvidarem dos potenciais danos que uma erupção solar pode produzir muitos especialistas estão divididos quanto às suas reais consequências. Alguns acreditam que um apagão de proporções continentais que afetaria milhões de pessoas poderia ser "administrável" se o religamento da rede fosse efetuado a um curto prazo de no máximo uma semana. Isto só seria possível se os danos elétricos fossem de pequena monta com poucos componentes danificados. Argumentam também que os sistemas atuais já estariam sendo equipados com sensores que desligariam a rede automaticamente antes que os transformadores pudessem ser afetados de forma irreparável.

Outros sugerem que uma enorme erupção causaria não só o desligamento da rede elétrica, como também danificaria transformadores e outros componentes críticos para a distribuição de energia antes da atuação dos sensores. Isto deixaria regiões inteiras sem eletricidade por meses ou até mesmo anos. Argumentam que os transformadores e outros componentes fundamentais da rede elétrica que podem sofrer danos permanentes alem de caros, não são peças sobressalentes disponíveis nas concessionárias distribuidoras. O fato é que, existe uma chance real de que uma grande supertempestade solar atinja a Terra e isto deixa todo mundo apreensivo com as potenciais consequências do evento.

O clima espacial está se tornando uma das preocupações em todo o mundo. A previsão de tempo espacial é realizada no Centro de Prognósticos Climatológicos Espaciais, da Agência Nacional Atmosférica e Oceânica dos Estados Unidos. A National Aeronautics and Space Administration NASA (Goddard Space Flight Center) possui satélites encarregados de monitorar o Sol continuamente observando a região das manchas mais propensas a entrar em erupção. Ainda assim, não se pode determinar com antecedência superior a quinze minutos a polaridade do campo magnético do plasma viajante em nossa direção para se avaliar precisamente o impacto coronal na magnetosfera. Caso a polaridade seja norte, o choque com o planeta será razoavelmente pequeno devido à deflexão com o norte magnético terrestre, mas se a torrente estiver orientada no sentido sul 
estará na direção oposta à do campo da Terra e a interação dos dois campos liberará grandes quantidades de energia.

È uma situação irônica constatar que um evento geomagnético extremo causará maiores danos às sociedades tecnologicamente mais avançadas, contrariamente ao que se observa na maioria dos desastres naturais onde os menos desenvolvidos são os mais atingidos. Um cataclismo desta natureza não deve causar qualquer impacto direto sobre as pessoas ou animais, mas como primeira consequência da ruptura da malha elétrica configura-se a escassez da água potável pela falta de energia para bombear e distribuir o liquido. O mesmo se aplica ao bombeamento e transporte dos combustíveis, com seus estoques reguladores de capacidade máxima para, na maioria dos casos um mês. Nas grandes cidades o transporte elétrico de trens e metrôs ficaria comprometido com milhões de pessoas imobilizadas nas vias publicas, estrangulando as rotas de transporte de alimentos e outros bens. A falta de água, saneamento básico e escassez de alimentos induziriam o caos social. Neste cenário não fica difícil prever a morte de muitas pessoas em questão de dias por falta de aquecimento/arrefecimento, Dentre as primeiras vítimas aqueles que necessitam de cuidados médicos e medicações de uso contínuo $\mathrm{Na}$ lista das provações, outros acontecimentos com desdobramentos de consequências imprevisíveis. Para a moderna sociedade o monitoramento do clima espacial assumiu caráter de vital importância. Conhecer com antecedência detalhes de uma tempestade geomagnética de grande magnitude é essencial para que se possa atuar a tempo nas grandes estações de geração de energia. Forçar um "black out" preventivo como forma de proteção do sistema elétrico até que a tempestade é fundamental. As preocupações com as consequências das tormentas geomagnéticas são tão grandes que a alem da NASA a Agência Espacial Europeia (ESA), está construindo um centro de vigilância permanente do Sol com previsão de funcionamento operacional para 2020.

\section{COMENTÁRIOS FINAIS}

É consenso que os efeitos mais significativos das tempestades geomagnéticas ocorrem nas latitudes mais altas. Neste contexto, para a posição geográfica do Brasil assume-se que os efeitos de uma tormenta solar extrema possam não ser tão significativos se comparados aos países das altas latitudes. Isto em relação à rede de energia elétrica. No entanto, satélites essenciais, como os de telecomunicações, posicionamento global, monitoramento do clima e território, podem ser seriamente afetados, implicando em dificuldades diversas de longo prazo. Apesar da localização privilegiada não se pode esquecer que os reflexos de um evento solar extremo nos países desenvolvidos exercerão enormes impactos econômicos em todo o mundo devido à interdependência econômica entre nações, contexto no qual o país se insere.

\section{REFERENCIAS}

BASU, S.; ANTIA, H.M. Helioseismology and Solar Abundance - Physics Report 457 (5-6) doi; 10.1016/jphysrep.2007.12.00.2. 2008.

CARRINGTON, R.C. Description of a Singular Appearance seen in the Sun on September 1, 1859".Monthly Notices of the Royal Astronomical Society 20: 13-5. Bibcode: 1859 MNRAS 20 $\underline{13 \mathrm{C}}, 1859$. 
GONZALEZ, W.D., J.A; JOSELYN, Y.; KAMIDE, H.W; KROEHL, G.; ROSTOKER, B.T. TSURUTANI, V. M. VASYLIUNAS. What is a Geomagnetic Storm? J. Geophys. Res., v. 99 (A4), 5771-5792. 1994.

LIMA-GUIMARÃES, S.T. de; CARPI JUNIOR, S.; BERROS, M.B.R.; TAVARES, A.C. Gestão de áreas de riscos e desastres ambientais G393 [recurso eletrônico] / - Rio Claro: IGCE, ,UNESP. RIO CLARO, SP. 20121 CD-ROM : il. ISBN 978-85-89082-25-9.

NERC - North American Electric Reliability Corporation. Effects of Geomagnetic Disturbances on the Bulk Power System. 3353 Peachtree Road NE Suite 600, North Tower, Atlanta, GA. February. 2012, 137p.

OFFICE OF RISK MANAGEMENT AND ANALYSIS. Geomagnetic Storms, Centra Technology. In: Report (14 January 2011). United States Department of Homeland Security. (downloaded) 2013.

OLIVEIRA; K. de; SARAIVA, M.F. Astronomia e Astrofísica. Editora Livraria de Física. Instituto de Física Universidade Federal do Rio Grande do Sul 2014. Disponível em pdf no site http://astro.if.ufrgs.br/livro.pdf

NASA - National Aeronautics and Space Administration. Solar Physics Marchall Space Flight Center. 04/02/2014. http://solarscience.msfc.nasa.gov/SunspotCycle.shtml/ acessada em 4 de fevereiro de 2014

NASA - National Aeronautics and Space Administration. SOHO Solar and Heliospheric Observatory. 04/02/2014. http://sohowww.nascom.nasa.gov/

http://www.cdcc.sc.usp.br/cda/producao/sbpc94/fems-04.jpg pagina visitada em 2 de março de 2014.

http://sohowww.nascom.nasa.gov/gallery/SolarCorona/combo001.html acessada em 2 de março de 2014

http://sohowww.nascom.nasa.gov/gallery/Helioseismology/large/mdi004_prev.jpg acessada em 4 fev 2014

"Timeline: The 1859 Solar Superstorm". Scientific American. July 29, 2008. Retrieved February 16, 2011

http://www.nasa.gov/mission_pages/soho/ acessada em 12 de abril de 2013

http://www.noaa.gov/satellites.html acessada em 12 de abril de 2013

http://www.inpe.br/crs/geodesastres/conteudo/publicacoes/conceitosbasicos.pdf acessada em $21 \mathrm{de}$ maio de 2013

http://sohowww.nascom.nasa.gov/ acessada em 22 agosto de 2013

http://www.scientificamerican.com/article.cfm?id=timeline-the-1859-solar-superstorm acessada em 23 de agosto de 2013 
http://zapper.xitizap.com/xitizap\%206/index_files/Page287.htm acessada em 29 de agosto de 2013 http://www.achetudoeregiao.com.br/astronomia/estrutura_sol.htm acessada em 2 de setembro de 2013

http://ultimosegundo.ig.com.br/ciencia/2013-03-30/cientistas-avaliam-consequencias-dastempestades-solares.html acessada em 2 de setembro de 2013

http://museumvictoria.com.au/collections/themes/2880/the-carrington-event-and-the-electrictelegraph-in-victoria pagina visitada em 24 de setembro de 2013 